\title{
GESTÃO ESCOLAR E O TRABALHO DOS EDUCADORES: DA ESTREITEZA DAS POLÍTICAS À COMPLEXIDADE DO TRABALHO HUMANO
}

\author{
Wanderson Ferreira Alves
}

\begin{abstract}
RESUMO: o objetivo do artigo é efetuar a crítica de alguns ideários que cercam as noções de gerir e de trabalhar, bem como evidenciar a amplitude e a complexidade dos aspectos que envolvem o trabalho humano. Trata-se de uma elaboração de natureza teórica e que se vale de estudos no campo da educação, mas, também, de estudos desenvolvidos no campo da sociologia do trabalho, da psicologia do trabalho e da ergonomia. As conclusōes apontam que uma racionalidade redutora das complexidades presentes nas situaçōes de trabalho comumente se apresenta nas ações da gestão, comprometendo a finalidade social das instituiçōes e repercutindo sobre os trabalhadores e trabalhadoras.
\end{abstract}

Palavras-chave: Trabalho. Trabalho docente. Gestão escolar. Ergonomia. Ergologia.

SCHOOL MANAGEMENT AND THE WORK OF EDUCATORS: FROM THE NARROWNESS OF GUIDELINES TO THE COMPLEXITY OF HUMAN WORK

ABSTRACT: This paper criticizes some ideas surrounding the notions of managing and working, ands pinpoints the broadness and complexity of the aspects involving human work. It is a theoretical elaboration that relies on studies in the fields of education, sociology of work, work psychology and ergonomics. Its conclusions suggest that the reductive rationality of the complexities present

Doutor em Educação e professor da Faculdade de Educação da Universidade Federal de Goiás (UFG).E-mail: wandersonfalves@yahoo.com.br 
in work situations is also commonly at work in the actions of management, compromising the social purpose of the institutions and having an impact on its employers.

Key words: Work. Teacher's work. School management. Ergonomics. Ergology.

\section{Indícios}

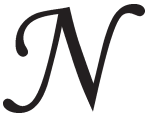

o início do ano de 2008, uma revista de grande circulação trazia em suas páginas de abertura uma entrevista com a secretária de Educação de São Paulo naquele período, a professora Maria Helena Guimarães de Castro. O tema central da entrevista era a iniciativa do governo paulista em implantar um sistema de bonificação pecuniária para as escolas que progredissem nos indicadores que aferem a aprendizagem dos alunos. $\mathrm{Na}$ entrevista, a referida iniciativa é apresentada como arrojada e inovadora, tendo em vista que o "objetivo é criar incentivos concretos para o progresso das escolas, a exemplo da bem sucedida experiência de outros países do mundo desenvolvido, como Inglaterra e Estados Unidos" (Castro, 2008). Perguntada sobre as críticas ao novo sistema, a secretária apontou como principal entrave o corporativismo sindical, pois, segundo ela, a qualidade do ensino tinha muito a ganhar com a nova lógica de remuneração, isto porque a "velha política da isonomia salarial passa ao largo dos diferentes resultados obtidos em sala de aula, e aí está o erro. Ao ignorar méritos e deméritos, ela deixa de jogar luz sobre os mais talentosos e esforçados" (idem, ibid.). Na sequência, a entrevistada explica que um dos graves problemas está na própria formação dos professores, inclusive das melhores universidades, visto que "se consagrou no Brasil um tipo de curso de pedagogia voltado para assuntos exclusivamente teóricos, sem nenhuma conexão com as escolas públicas e suas reais demandas" (idem).

Em 2009, Maria Helena Guimarães de Castro foi substituída. Para seu lugar foi chamado o ex-ministro da Educação Paulo Renato de Souza. O novo secretário assumiu prometendo manter as linhas gerais da política até então adotada e, em entrevista recente, explicou onde está o cerne do problema da qualidade do ensino em São Paulo. Segundo ele, a rede pública tem evoluído, mas não se está melhor "por causa da formação dos professores, um problema nacional. Quando fui ministro quis 
que a formação estivesse mais voltada ao que é trabalhado na sala de aula" (Souza, 2009).

É interessante notar que o trabalho, no caso o trabalho do professor, se mostra como uma obviedade, um conjunto de elementos claramente identificáveis e racionalmente manipuláveis. Reduzido a objeto, o que aparece é um conjunto de variáveis (formação, material didático etc.) disponíveis ao interesse instrumental da gestão.

Todavia, tal racionalidade não é prerrogativa deste ou daquele estado da Federação. Por exemplo, em Goiás, na primeira metade dos anos 2000, tendo em vista promover a reforma do ensino médio, a secretaria de Educação organizou uma série de ações, cujo destaque parece ter sido dado à "capacitação" dos professores. As referidas ações foram várias: contratação de assessoria para elaboração do projeto de reforma, organização de seminários, planejamento das etapas, sistema de acompanhamento das escolas, capacitação dos professores através das telessalas, formação em nível superior para os professores que ainda não possuíam formação específica etc. Obviamente, algumas dessas ações podem possuir méritos, mas, conforme estudo desenvolvido por Alves (2009), é forçoso reconhecer que, do ponto de vista estrutural, o trabalho dos professores não foi objeto da devida atenção e até dispositivos que poderiam garantir alguns ganhos, como o estatuto e plano de cargos e salários obtido no ano de 2001, se tornaram quase que inoperantes diante da dinâmica das situações de trabalho dos professores nas escolas. $\mathrm{Na}$ referida pesquisa, alguns professores do ensino médio chegavam a lecionar mais de 60 horas-aula semanais, espalhando suas aulas por turnos, turmas, escolas e redes de ensino. Todavia, formações (cursos de capacitação) foram oferecidas e uma reforma projetada, tal como um grande cobertor que, no intervalo de cinco, seis anos, recobriria as escolas goianas.

Como se depreende, os gestores elegem causas e soluções, tendo em vista o desenvolvimento de seus respectivos projetos. No entanto, é importante observar que, tanto nas causas como nas soluções eleitas, o contexto em que o trabalho é realizado jamais é questionado: as situações de trabalho na escola formam uma evidência, não uma problemática. É claro que aí se misturam senso comum, conservadorismo etc., mas não somente. Também estão presentes modos de se compreender o que é o trabalho humano, modos de se conceber o que é a gestão e o que é trabalhar. $\mathrm{O}$ trabalho aqui aparece como algo conhecido e dominado. 
Contrariando as colegiais certezas de alguns secretários, o trabalho humano parece ser uma realidade bem mais complexa. ${ }^{1}$

A tese aqui sustentada é a de que parte dessas políticas em educação, como as ilustradas nos parágrafos anteriores, embora se apresentem como avançadas, tendem a esposar ideários que transitam mais amplamente no mundo do trabalho, mas que também no campo educacional se fazem presentes e pautam uma compreensão restrita do que é a gestão e o próprio trabalho humano. Tais ideários possuem contornos que vão bem além dos estabelecidos pelo campo da educação. Porém, na dialética entre geral e particular, também se expressam entre seus atores sociais, entre os quais, pela natureza de suas funções de gestor e amplitude da repercussão de suas ações, ganham natural proeminência os secretários e secretárias de Educação estaduais e municipais.

Assim, o objetivo do presente artigo é efetuar a crítica de alguns ideários que comumente cercam as noçôes de gerir e de trabalhar, bem como evidenciar a amplitude e a complexidade dos aspectos que envolvem o trabalho humano. O texto se vale de produções teóricas e empíricas elaboradas no campo da educação, mas, também, no âmbito da sociologia do trabalho, psicologia do trabalho e da ergonomia. ${ }^{2}$ Está assim organizado: em um primeiro instante, são apresentadas algumas situaçôes que sinalizam um pouco das complexidades que envolvem o trabalho humano; em seguida, o paradigma taylorista e sua racionalidade são examinados e problematizados, particularmente em suas repercussões sobre a compreensão do que é "trabalhar"; na sequência, algumas contribuições da ergonomia da atividade são apresentadas, evidenciando a complexidade do trabalho e os saberes dos trabalhadores; na última seção, são apresentadas as considerações finais.

\section{Três exemplos sobre o gerir e o trabalhar}

A partir de profissões e setores econômicos diferentes, três exemplos ajudam a ilustrar os paradoxos e as complexidades que circundam o trabalho humano. Vejamos cada um deles a seguir.

Primeiro exemplo: o bancário no estudo de Codo (2004, p. 192-193):

O banco estudado é uma gaiola de ouro. Um lugar privilegiado para se trabalhar no Brasil de hoje. Bom salário, estabilidade no emprego, exceto 
algumas reclamaçóes quanto ao ar condicionado (ou por alergia, ou porque os computadores exigem um ambiente mais frio que o habitante de Ribeirão Preto gostaria), nenhum fator responsável por insalubridade. $\mathrm{O}$ turn-over é baixo, a busca pelo concurso para ingresso no banco é altíssima. O trabalho é limpo, não existem sinais de que a carga de trabalho seja particularmente pesada, enfim, tudo leva a crer que se encontraria ali um trabalhador satisfeito com a sua profissão.

No entanto, quando você pergunta ao trabalhador sobre a satisfação no trabalho, poderá ouvir respostas como essas:

(...) "Mas a primeira coisa é sair daqui porque eu não gosto disso de jeito nenhum (expressão de nojo). Acho isso aqui terrível, pior que linha de montagem trabalhar aqui, é todo dia a mesma coisa... Faço um servicinho gostoso hoje que vou te falar (irônica), mais inútil do que... sei lá o que. Lembra aquele pessoal do IBGE que sai por aí fazendo o censo? Um mês depois de ter começado já tinha acabado tudo. Aqui nunca acaba”.

Nesse estudo com funcionários de um banco estatal, Codo (2004) chama atenção para o que denomina de síndrome do trabalho vazio e para a depressão que acomete parte desses trabalhadores. Nos casos relatados por ele, como o exposto no trecho anterior, é curioso observar que, mesmo em situações onde se tem ambiente seguro, limpo, ar condicionado etc., a relação entre o trabalhador e o trabalho não se apresenta necessariamente sem dificuldades. A subjetividade não pode ser posta entre parênteses, simplesmente colocada em suspensão no exercício profissional, e o trabalhador pode sim, mesmo nessas condições, sofrer com o trabalho que realiza, não se reconhecer em nada que desenvolve e, afinal, não estar bem, nem com os outros, nem com si mesmo. p. 72):

Segundo exemplo: a operária nos estudos de Duraffourg (2007,

Eu me lembro de uma operária num atelier de confecção. Ela estava mal instalada, o espaço de trabalho entulhado, havia ruído, vapor, ela estava sobre pressão etc. Em resumo, não havia necessidade de procurar muito para verificar os problemas de condições de trabalho, no sentido clássico do termo. Mas do que ela falava em primeiro lugar, o que ela sofria em primeiro lugar não era aquilo. Vinda de sua Itália natal, ela fabricava calças há vinte anos. Hoje lhe exigem, como ela mesma diz, "nada de refinamento, pois assim você perde tempo e nós perdemos dinheiro" [o contexto é o da expansão do modelo de produção por sobrequalidade, ou seja, produção com patamares qualitativos diferenciados de acordo com 
a faixa do mercado de destinação do produto]. Eu ainda a vejo pegando uma calça, me mostrando e dizendo: "você vê, me obrigam a fazer esta merda!". Porque sua empresa fabrica cada vez mais para tal cadeia de grandes lojas, ela não deve mais trabalhar como ela aprendeu. E isto é para ela insuportável, muito mais que suas condiçôes materiais de trabalho.

Com Duraffourg (2007), ergonomista, o exame da questão é remetido à situação de trabalho, portanto, a um conjunto de aspectos que se conjugam em determinado contexto e aos aspectos concernentes à atividade do trabalhador. No exemplo dado, importa notar a relação de sentido estabelecida entre o trabalhador e o trabalho: a preocupação da operária com a qualidade do que produz, seu desconforto mediante a consciência de que está desenvolvendo algo de qualidade bem abaixo do que seria capaz de realizar. $\mathrm{O}$ autor sublinha que as pessoas não são indiferentes ao que realizam e que a eficácia da ação (que não deve ser confundida com produtividade) participa do sentido do trabalho. Em suas palavras, é necessário "refletir sobre o que há de patogênico no fato de se exigir das pessoas que elas não façam o melhor que elas podem. No plano axiológico é algo terrível” (p. 72).

Terceiro exemplo: segurança e trabalho nos estudos de Lima (2007, p. 103):

[A PETROBRÁs] ao mesmo tempo em que diminuía seus efetivos, aumentava a contratação das empreiteiras (...). No entanto, os pesquisadores [ela se refere à pesquisa de Ferreira \& Iguti, 1996] constatam que tudo isso se deu de forma precária, ressaltando algumas consequências nefastas dessa prática: o aumento das desigualdades, a maior exposição aos riscos e, em decorrência do caráter temporário dos contratos, o surgimento de certas barreiras, impedindo o acúmulo de conhecimentos e a consolidação de compromissos entre os membros da equipe. Alguns depoimentos [dos operários] são reveladores:

"O serviço é temporário. Fazem e vão embora. Deu problema, quem vai responder?”.

"Você fica treinando pessoas da empreiteira (...). O pessoal que você treinou, no próximo contrato não está mais lá (...)".

(...) Tudo indica que a falta de continuidade das equipes impossibilitava o acúmulo de conhecimento ou, na perspectiva de Clot, impedia o desenvolvimento e a consolidação do gênero da atividade. Isso aumentava as chances de ocorrência de acidentes, sobretudo se levarmos em conta 
que estamos lidando com um processo de trabalho complexo, envolvendo enormes riscos e que, por isso mesmo, exige muita experiência acumulada para se alcançar certo domínio.

No estudo apresentado por Lima (2007), o objeto de análise é a repercussão de determinadas ações da direção da empresa (política de pessoal e gestão) nas situações concretas de trabalho, ocasionando precarização das condições laborais e agravamento dos riscos de acidentes. A PETROBRÁs, vale sublinhar, possuía baixo índice de acidentes até o início dos anos de 1990, situação que se modifica ao longo da mesma década até culminar, em 2001, com o afundamento da plataforma P36. ${ }^{3}$ Mas o que foi exatamente tocado quando a política de terceirização foi impulsionada e os coletivos se tornaram crescentemente móveis? A hipótese da autora é de que tais políticas fragilizaram o coletivo, de tal maneira que o saber dos trabalhadores já não podia se consolidar e permanecer como patrimônio em comum e partilhado. Nesse sentido é que ela se refere à noção de gênero profissional desenvolvida por Clot (2006). O gênero profissional, explica o referido autor, é a memória social da profissão.

Os três exemplos anteriormente apresentados ajudam a dimensionar como o trabalho é uma realidade mais enigmática do que comumente se supõe. O emprego oferecia bom ambiente de trabalho, carreira, entre outros atrativos. Então, por que o bancário se apresentava altamente insatisfeito? Por que a operária do setor de confecções se preocupava com a qualidade das peças de roupas que produzia, já que estas atendiam ao padrão determinado pela empresa? Por que a gestão da PETROBRÁs não considerou a repercussão de suas ações sobre as situaçôes de trabalho dos operadores? Ou, ainda nesse exemplo, o que exatamente esse coletivo de trabalhadores colocava em marcha no dia a dia, nos terminais e plataformas, e que foi afetado pela gestão da empresa? Esses exemplos, cada um ao seu modo, explicitam como o que está efetivamente em jogo no trabalho ultrapassa e transborda o indicado nos planos dos gestores, organogramas, contratos... Contudo, também fazem pensar sobre o curto alcance de termos tão comuns à gestão, como "recursos humanos", "motivação", "treinamento", entre tantos outros. Seja como for, esses termos testemunham a ambição humana de identificar, compreender e agir diante das realidades e exigências próprias ao mundo do trabalho. Todavia, entre ambicionar e realizar existem muitas mediações. 
As relações e processos que aí se constituem estão longe de serem transparentes e o próprio sistema social obscurece as marcas da humanidade em sua produção e reprodução. Afinal, como bem lembra um cavaleiro do século XIX, nosso sistema tende a transformar o social em quase-natural. Assim, temos que, por um lado, a intransparência está longe de ser uma anomalia; por outro, que a passagem pelo trabalho concreto (as diferentes formas laborais, o processo de trabalho, a gestão, as tecnologias etc.) igualmente não o apresenta como uma realidade imediatamente visível. De todo modo, essa ambição de conhecer e dominar há muito perpassa o gênio humano (p. ex., Descartes) e, com o quadro sócio-histórico da Revolução Industrial e do capitalismo nascente, viu aprimorar e emergir novas formas de explorar a força de trabalho de homens e mulheres. O taylorismo foi sua grande expressão: suas repercussões transcenderam, e muito, os limites estritos das fábricas e talvez tenham nos deixado marcas indeléveis.

Diante desse projeto deliberado de racionalização máxima da atividade laboral, o "trabalhar" é concebido como lugar da repetição, do idêntico, do mero fazer, enfim, da ação desprovida de pensamento, pois tudo já teria sido pensado por outrem. ${ }^{4}$ Como sublinha Schwartz (2000), mais que um modo de gerir a produção, o taylorismo instituiu certa perspectiva cultural e filosófica na compreensão do que é a atividade humana. O taylorismo, explica Schwartz, assinala um momento histórico no âmbito do trabalho humano e, por essa via, se encontra com a cultura e com o desenvolvimento contraditório das civilizações. Em perspectiva, um pensamento dominante no uso produtivo dos seres humanos, sistema organizador de grandes empresas do Ocidente, mesmo que sem eliminar as demais formas de organização da produção. ${ }^{5}$ Sob tal paradigma, milhões de trabalhadores e trabalhadoras conduziram suas vidas por decênios, por gerações... Os sulcos que tal racionalidade produziu talvez sejam mais profundos do que comumente se supõe. Se multidões de homens e mulheres eram solicitadas a trabalhar "sem pensar" (sans penser), seria preciso refletir em que medida isso atravessou o horizonte dos sistemas educacionais, a vida cotidiana e o meio social das nações (Schwartz, 2000).

\section{Governar e simplificar}

$\mathrm{Na}$ Europa, entre os anos de 1810 e 1820, aponta Vigarello (2003), em silêncio, sem nenhum alarde, uma série de mudanças, rupturas mesmo, se processou nos modos de pensar e abordar a eficácia do 
corpo humano, então assimilado a um corpo-máquina. Este corpo será contabilizado e a ação, mesmo o gesto ginástico, será progressivamente racionalizada. Por exemplo, P. H. Clias, diretor do Ginásio de Berna (Suíça), em 1815, discorre sobre os resultados de um de seus alunos:

A força de pressão de suas mãos dobrara (em cinco meses); com seus braços, ele se erguia a três polegadas do chão, e ficava assim, suspenso, durante três segundos; ele saltava três pés de largura, percorria cento e sessenta e três passos em um minuto e carregava, neste mesmo período de tempo, um peso de trinta e cinco libras sobre os seus ombros [-um ano depois-] ele saltou, com impulso, seis pés de largura e percorreu quinhentos passos em dois minutos e meio. (Buchez \& Trélat, apud Vigarello, 2003, p. 10)

Como bem destaca Vigarello, essas constatações aparentemente sumárias são, na verdade, determinantes, no sentido que permitem não somente apreciar performances, mas também as capacidades corporais, conforme unidades que viabilizam a comparação para além de contextos particulares. Ora, como entender o que ali ocorre? O que no tecido social se modifica? Argutamente, o autor observa que, para compreender o contexto em que tais mudanças acontecem, é preciso considerar "a vontade muito marcada (entre os fins do século XVIII e início do século XIX) de calcular capacidades, com a finalidade de obter um melhor rendimento e um desejo de medir os movimentos para melhor economizá-los". Isso porque, explica Vigarello (op. cit., p. 14), "Dispositivos industriais embrionários impõem já uma estrita fiscalização dos movimentos e dos custos (...)".

Como se depreende, o quadro social e econômico da modernidade ofereceu elementos para novos modos de se pensar a atividade laboral e, a rigor, o próprio corpo humano foi objeto de uma crescente preocupação, tendo em vista medi-lo, quantificá-lo e avaliá-lo. No início do século XX, o taylorismo e todo um movimento que ficou conhecido como Organização Científica do Trabalho são emblemáticos dessa ambição de racionalização que, até então, se mostrava dispersa e pouco sistematizada. Com o peso de sua excessiva presunção e contradiçóes, destaca Schwartz (2000), o taylorismo forja uma formidável máquina de pensar o trabalho humano, agora em dimensões universais. Seja como for, do engenheiro (Taylor) ao capitalista industrial (Ford), a planificação prossegue e incorpora novas dimensões e, talvez, ainda que por outras vias, 
sua racionalidade não tenha se apagado nos mais modernos sistemas de gestão. ${ }^{6}$ Assim, retomando a problematização da Organização Científica do Trabalho, o corpo no ato laboral é concebido como subordinado ao conceito (os engenheiros, os técnicos do setor de métodos...) e à cadência do tempo: acelerar o andamento da linha é acelerar o gesto humano e aumentar o volume da produção (intensificação do trabalho).

Schwartz (2000) chama a atenção para alguns aspectos na forma e na lógica organizativa do taylorismo. Um desses aspectos é a instituição de uma racionalidade única, pois se a operação a ser realizada havia sido minuciosamente estudada e adequadamente instruída nos modos de proceder, então, havia somente the one best way, ou seja, a melhor maneira de se fazer. Outro aspecto é a secção entre concepção e execução, pressuposto lógico do postulado anterior e que remete às relações de poder, mas, também, a uma maneira de compreender as potencialidades das pessoas e julgá-las a partir de uma suposta desigualdade funcional: a perspectiva do the one best way é edificada sobre os conhecimentos conferidos pela mecânica, pela cinemática... de modo que a ciência explica o ato laboral do operário, mas o operário mais talentoso, dirá Taylor, é incapaz de compreendê-la. Enfim, todo um conjunto de especialistas projeta estandardizar o momento produtivo, o que deriva na tentativa de eliminar as singularidades da situação. A imagem cultural do trabalho como rotina, atividade mecânica e repetitiva é, de certo modo, o corolário da distinção entre concepção e execução.

Outros aspectos poderiam ser aqui desenvolvidos, como a problemática que circunda a individualização das tarefas e as relações hierárquicas, mas, para os fins e limites de um artigo, parece já termos avançado o suficiente para, ainda que de maneira sucinta, evidenciar aspectos centrais do taylorismo e seu significado na história da humanidade que, como vimos, vai bem além do estritamente econômico. A Organização Científica do Trabalho, vale ainda dizer, expressa a ambição de tudo racionalizar no ato laboral.

Tendo chegado a esse momento da reflexão, talvez seja oportuno efetuar algumas indagações: o trabalho, efetivamente, é apenas execução das instruções dadas por outrem? Qual o alcance da proposição de que somente há uma "única e melhor maneira de se fazer"? À medida que adentramos a "batalha do trabalho real", para utilizar uma conhecida expressão de Alain Wisner, essa proposição se sustenta? 


\section{Situando as questôes}

À medida que se expandiu, expressando nesse movimento um modo de organização da produção, uma lógica de relações na empresa, delineando uma maneira de pensar o trabalho, ao passo que ascendia em importância econômica, o taylorismo se mostrou como um objeto a interrogar diversos campos do conhecimento. Assim, no decorrer do século $\mathrm{xx}$, foram vários os pesquisadores que se propuseram a abordar, em estudos teóricos ou empíricos, o taylorismo e o movimento da Organização Científica do Trabalho. Em meio a tudo isso, em alguns países, como a França, uma tradição crítica e politicamente engajada com o movimento sindical e com as lutas sociais se fortaleceu. Este foi o caso da sociologia do trabalho, que formou "uma tradição de denúncia dos efeitos nocivos da técnica e da organização do trabalho sobre o homem. Na França, a sociologia do trabalho rima com crítica ao taylorismo, dentro do espírito de Georges Friedmann, que foi o primeiro a sistematizar as pesquisas empíricas sobre o trabalho operário" (Linhart, 2007, p. 15). Entre as disciplinas que estudam o trabalho, tendo em vista as questôes que estão sendo problematizadas no presente texto, uma trouxe contribuiçōes fundamentais e, por isso, merece ser destacada: a ergonomia da atividade. $^{7}$

A ergonomia é um campo que articula conhecimentos de várias disciplinas com o objetivo de conhecer e transformar o trabalho. Um de seus postulados de base é a distinção entre trabalho prescrito e trabalho real. $\mathrm{O}$ primeiro compreende o que antecede a atuação do trabalhador, por exemplo, no caso de um professor, o sistema de avaliação adotado pela escola ou o plano de curso de uma disciplina; ${ }^{8}$ o segundo, o trabalho real, compreende o efetivamente realizado diante da realidade concreta e de suas dinâmicas. A mediação entre o trabalho prescrito e o trabalho real exige a atividade do trabalhador. A ergonomia de base francesa, mesmo que não homogênea, esposa em larga medida a noção de atividade.

As contribuições da ergonomia, ao buscar o ponto de vista da atividade, colocaram em evidência, de maneira inequívoca, o saber dos trabalhadores e todo um quadro bem mais denso e complexo no tocante ao trabalho humano. Ensinaram que devemos levar a sério o trabalho que, em sua aparência, geralmente acreditamos ser simples. Também chamaram a atenção para o fato de que uma compreensão restrita do trabalho 
comumente se apresenta nas ações da gestão, o que compromete os objetivos socialmente fixados para a instituição (escola, hospitais, serviços públicos de transporte urbano, indústrias etc.) e resulta em consequências para os trabalhadores.

Duraffourg (2007) narra o caso de um competente engenheiro de automação que é bastante ilustrativo dessas questôes. O autor conta que, certa vez, quando participava de um seminário sobre o tema da gestão e as novas formas de se conceber o trabalho, um jovem engenheiro da automação estava entre o público participante e aparentava não estar compreendendo bem o sentido dos problemas ali apresentados. Isso, conta Duraffourg, até que lhe deu um "estalo" e o engenheiro contou a seguinte história:

Fui chamado por uma queijaria para ver se não havia um meio de automatizar a viragem dos queijos na fase da afinação do produto. Virar queijos não é um problema muito complicado para mim. Fui ver as instalações, fiz meu trabalho com seriedade, concebi e implantei um robô que vira os queijos. E meu robô funciona muito bem: ele "vê" um queijo e paf [ele faz o gesto] - ele o vira, nenhum problema. Alguns meses mais tarde, o patrão me chama; existem problemas de qualidade, a frequência das reclamações de clientes aumentou e ele tinha até perdido fatias de mercado. É a afinagem que tem problemas, ele me diz. Como engenheiro de automação, eu não compreendo. Eu fui lá ver: ora, meu robô funciona muito bem, "ele vê" um queijo e paf, ele o vira. Mas me vem agora na memória que as operárias, que faziam esta operação manualmente, não viravam todos os queijos: elas pegavam alguns, tocavam-no, às vezes os cheiravam e não os viravam. Talvez esteja aí o problema do meu robô. (Duraffourg, 2007, p. 67)

Virar os queijos, observa Duraffourg, era uma tarefa bem mais complicada do que se supunha, embora tivesse sido reduzida a uma sucessão repetitiva de gestos. $\mathrm{Na}$ verdade, "cada gesto da operadora é o resultado de um diagnóstico que mobiliza seu nariz, sua sensibilidade tática, seu cérebro, é claro, a fim de tomar a cada vez uma decisão capital no que diz respeito à qualidade" (idem, ibid.). Neste caso aqui relatado, a visão simples do que é o trabalho redundou, afinal, na grave decisão da gestão pela supressão dos empregos das operárias. Como se depreende, nas questóes atinentes ao trabalho, uma perspectiva restrita não beneficia ninguém e, pela posição que ocupa diante a propriedade privada dos 
meios de produção, não deixa incólume trabalhadores e trabalhadoras das mais variadas ocupaçōes e profissões.

As implicações de tal perspectiva restrita incidem inclusive sobre a saúde das pessoas no trabalho. Por exemplo, a partir do caso de uma pesquisa que realizaram, no fim dos anos de 1960, em uma empresa eletroeletrônica, Teiger et al. (2004) relatam que, quando a fábrica foi criada, esta se mostrava como diferenciada das demais da região: "moderna, aquecida, bem iluminada e limpa, onde as mulheres trabalhavam em sua maioria em posição sentada, sem esforço físico visivelmente significativo" (p. 138). Enfim, tudo parecia muito promissor. Todavia, retomando os documentos das centrais sindicais naquele período, os autores identificam que, no primeiro momento, os problemas essenciais se relacionavam à saúde das trabalhadoras (mulheres jovens eram a maioria) e à organização do trabalho, ao salário ligado ao rendimento (pagamento de bonificação), aos ritmos e às condições de trabalho e de vida. Após esta constatação, afirmam: "'a fadiga física e mental' passa a ser citada e os desmaios e as crises nervosas que ocorrem na linha de produção são denunciados" (p. 139, grifo dos autores). O que os documentos sindicais apontavam não era ficção. Os autores informam que, com o passar do tempo, a empresa se viu diante de três problemas: o absenteísmo crescente $(30 \%)$, rotatividade (em torno de $22 \%$ ) e de qualidade da produção.

Ora, o que acontecia entre o invólucro dessa empresa (suas formas aparentes) e a dinâmica das situações de trabalho das operárias? $\mathrm{O}$ mais interessante nesses estudos que focalizam o trabalho a partir da abordagem ergonômica é a compreensão de como soa deslocado e ideológico (no sentido de mistificação da realidade) o discurso de que as pessoas não querem trabalhar, que elas não procuram empregos... Um discurso que desloca um problema de natureza estrutural para o âmbito individual. Veja bem, no caso relatado, tínhamos $22 \%$ de rotatividade entre o pessoal da empresa, 30\% de absenteísmo e alguém diz que as pessoas não estão "interessadas"! Talvez, ironiza Duraffourg (2007), as pessoas recusem isso que está aí, isso que lhes oferecem como trabalho. O deslocamento do problema para o foro individual é perfeitamente convergente com uma visada sobre o trabalho que não interroga os aspectos que estão em seu cerne, mas que tão somente os circunda.

O problema da formação em serviço (p. ex., os cursos, programas etc.) oferecida pelas empresas é também paradigmático. Como explica 
Duraffourg (2007), muitos dos problemas nas empresas são tratados assim: as situaçôes concretas e o ponto de vista dos que estão ali trabalhando não são considerados, ao passo que a formação vem para adaptá-los. $\mathrm{O}$ autor exemplifica com a questão da higiene e segurança no trabalho:

Há um campo em que isto é particularmente perceptível: o da higiene e segurança no trabalho. O primeiro reflexo quando há ruído é... protetor de ouvido; quando há um risco de acidentes é... formação etc. (...). Quando lombalgias ou acidentes de levantamento e manutenção de cargas são observados na empresa, é frequente que ela faça a demanda de ações de treinamento sobre "gestos e posturas". É o exemplo típico de uma questão - a manutenção - isolada arbitrariamente do resto: ela é, habitualmente, tratada independentemente da concepção dos locais de trabalho, da pressão do tempo, da imbricação de tarefas etc.; independentemente mesmo do que preocupa o trabalhador em situação real. De fato, em formação, o trabalhador deve se abstrair disso: esquecer o espaço entulhado, o saco dificilmente acessível atrás da pilastra, as sequências repetitivas de levantamento e manutenção de cargas, o prazo a respeitar, a preocupação com o formulário de pedido etc. Tudo isso está em jogo quando trabalhamos, não pensamos em primeiro lugar em nossa coluna. Devemos nos surpreender que os resultados sejam na maior parte do tempo tão decepcionantes? (p. 59-60)

Na sequência, Duraffourg aponta que esse é um modo de ver as pessoas como o problema e, ao final da formação, se as práticas não mudaram, os responsáveis estão eleitos: "se eles têm lombalgias, acidentes, é culpa deles, eles não sabem fazer a manutenção, eles se comportam mal, eles não prestam atenção etc.” (p. 60). Uma lógica como esta, afirma o autor, faz com que os contextos jamais sejam questionados e que prevaleça a adaptação. Ora, isso parece distante do que os nossos professores e professoras experienciam nas escolas? A cada nova reforma curricular, promulgação de lei, método de avaliação, projeto inovador... a resposta é: formação. A organização do trabalho escolar - sua estrutura, modelo de funcionamento, condiçôes de trabalho etc. - resta pouco ou nada alterada.

Portanto, no que se refere à formação contínua ou em serviço dos professores nas escolas, uma política educacional que projeta açôes sobre a formação, deslocando-as das coerções e demandas ligadas às situações de trabalho na escola, arrisca a se apresentar como uma concepção meramente adaptativa na relação homem-trabalho. Como vimos na seção 
inicial do presente texto, certamente alguns secretários de Educação poderiam se reconhecer aqui.

\section{Considerações finais}

A dificuldade da gestão no tocante ao trabalho não parece provir deste ou daquele aspecto, mas de uma conjugação de instâncias que podem, em cada caso, se dispor de vários modos. É certo que muitos aspectos (p. ex., demandas da hierarquia institucional, restrições orçamentárias, entre outros) podem concorrer para as decisões tomadas por especialistas, gestores ou pelos que ocupam posições de chefia, cujas ações repercutem sobre coletividades. É certo também que essas decisões são tomadas a partir de critérios que hierarquizam o que será realizado. Portanto, elegem prioridades. Aqui está o ponto importante: dissimuladas por sua visibilidade (realidade óbvia, dirão), as questões concernentes ao trabalho são decisivas para a finalidade social de uma instituição e são comumente secundarizadas. Como o leitor pôde acompanhar nas seções anteriores, esse não é um problema restrito ao campo educacional, mas uma contradição que atravessa mais amplamente o mundo do trabalho, o que somente vem ratificar as dificuldades com que se defrontam os interessados em compreender e transformar o trabalho.

O problema em tela comporta uma dimensão eminentemente política. Daí que a atenção aos saberes dos trabalhadores e ao que eles movimentam no trabalho é importante. Assim, as questões que foram abordadas no presente texto tocam em aspectos relativos à saúde, condições de trabalho, consciência e ação política. Nesse ponto, o trabalho em comum entre universidade e sindicato parece algo a ser fortalecido. Este último, por ser uma instituição que luta por "outros usos" da força de trabalho. ${ }^{10}$ A primeira, pelo horizonte que o rigor dos conceitos pode oferecer, ao passo que possibilita igualmente que os próprios conceitos se renovem no encontro com a experiência histórica dos homens e mulheres trabalhando. Nessa direção, temos ainda um continente pela frente.

Por último, vale ainda uma observação em relação ao taylorismo. Como foi possível acompanhar, ele compreende uma lapidar projeção do cientificismo sobre o "trabalhar", sendo, por conseguinte, paradigmático de uma concepção instrumental da atividade humana; projeto tanto ambicioso como ilusório. Isto por dois motivos, entre outros: primeiro, 
porque o trabalho não é uma simples execução, os ergonomistas incansavelmente o sublinharam com a distinção entre trabalho prescrito e trabalho real; em segundo lugar, porque é impossível para os seres humanos, no trabalho, suprimirem sua subjetividade, se colocarem em suspensão, eliminarem suas aspirações, seu corpo, se impedirem de pensar, como apontava Canguilhem (2001) ainda nos anos de 1940.

Prolongando um pouco mais o pensamento de Canguilhem, temos que a relação entre o homem e o meio onde desenvolve seu trabalho comporta inúmeras interrogações, não tendo nada de evidente ou simples, a não ser que acreditemos que o meio compreende uma soma de excitantes, em função da qual o ser vivo só faz reagir. Isso não faz lembrar algumas ações (pagamento de bônus...) de nossas políticas educacionais?

\section{Recebido em maio de 2009 e aprovado em dezembro de 2009.}

\section{Notas}

1. Não é o caso de se explorar todo o conjunto de dificuldades que tais linhas de argumentação e propostas de ação esboçadas nos parágrafos anteriores apresentam, por exemplo, na informação de que as mencionadas políticas de premiação são exitosas nos países que as adotam nas escolas. Para uma excelente análise crítica das atuais políticas educacionais em curso nos países anglo-saxônicos, cf. Cribb \& Ball (2005).

2. O campo da educação possui uma história que precisa ser considerada e valorizada, no tocante aos estudos sobre o tema das políticas educacionais e o tema da gestão escolar, no que testemunham as produções teóricas de autores como Vitor Paro, Dalila Andrade Oliveira, José Carlos Libâneo, Sofia Lerche Vieira, João Ferreira de Oliveira, Luiz Fernandes Dourado, apenas para citar alguns. Todavia, é possível que o diálogo com disciplinas que têm o trabalho como preocupação primeira em suas investigações, algumas delas com um lastro de décadas de investigação sobre o tema, possa enriquecer essa discussão. Veremos se, ao longo do texto, tal apontamento se confirma.

3. A autora enfatiza que as causas dos acidentes são múltiplas, portanto não circunscritas ao problema em tela, apontado aqui como tão somente um de seus importantes determinantes.

4. "não pedimos a eles para pensar", dizia Taylor, sem dissimular as palavras (cf. Schwartz, 2000)

5. Vale advertir que não existe uma forma "pura" de taylorismo ou de fordismo, pois concretamente as situações entre empresas, regiōes e países são diversas. Ademais, mesmo o argumento sobre o fim de uma forma (p. ex., a noçāo de "pós-fordismo") é igualmente impreciso. Nesse âmbito, devem-se evitar simplificações (cf. Linhart, 2007, p. 25 e ss.).

6. Isso porque essa racionalidade não se exprime em forma, mas em formas. Em um sistema econômico que se funda na extração de mais-valia, suas feiçôes podem ser várias, ainda 
que sua finalidade última não se altere. Por isso, o toyotismo não elimina a questão, repondo por outras vias uma concepção formalista da atividade humana.

7. Para uma compreensão dos aspectos históricos e epistemológicos da ergonomia, cf. Daniellou et al. (2004).

8. O conjunto de aspectos que integram o prescrito é bastante amplo e o próprio trabalhador pode elaborar prescritos para si mesmo.

9. Depois dos anos de 1970, repercutindo a psicologia soviética com os estudos de Leontiev e Vigotski, a ergonomia encontra a noção de atividade, conferindo-lhe valor heurístico na análise das situações de trabalho.

10. A esse respeito, cf. Di Ruzza \& Schwartz (2003).

\section{Referências}

ALVES, W. A formação contínua e a batalha do trabalho real: um estudo a partir dos professores da escola pública do ensino médio. 2009. 343f. Tese (Doutorado em educação) - Faculdade de Educação, Universidade de São Paulo, São Paulo.

CANGUILHEM, G. Meios e normas do homem no trabalho. Pro-Posiçôes, Campinas, v. 12, n. 2-3, p. 109-121, jul./nov. 2001.

CASTRO, M.H.G. Entrevista. Veja [on line], São Paulo, ed. 2.047, 13 fev. 2008. Disponível em: <http://veja.abril.com.br/130208/ entrevista.shtml> Acesso em: mar. 2010.

CLOT, Y. A função psicológica do trabalho. Petrópolis: Vozes, 2006.

CODO, W. Prototeoria: síndrome do trabalho vazio. In: Codo, W. (Org.). O trabalho enlouquece?: um encontro entre a clínica e o trabalho. Petrópolis: Vozes, 2004.

CRIBB, A.; BALL, S. Towards an ethical audit of the privatization of education. British Journal of Educational Studies, Oxford, v. 23, n. 2, p. 115-128, jun. 2005.

DANIELLOU, F. et al. (Coord.). A ergonomia em busca de seus principios: debates epistemológicos. São Paulo: E. Blücher, 2004.

DI RUZZA, R.; SCHWARTZ, Y. Da atividade militante à elaboração de saberes. Education Permanente, Nancy, n.154, p. 1-9, 2003. Disponível em: <www.ergologie.com>. Acesso em: 15 abr. 2008. 
DURAFFOURG, J. O trabalho e o ponto de vista da atividade. In: SChwartz, Y.; Durrive, L. (Org.). Trabalho e ergologia: conversas sobre a atividade humana. Rio de Janeiro: UfF, 2007.

FERREIRA, L.; IGUTI, A. O trabalho dos petroleiros: perigoso, complexo, contínuo e coletivo. São Paulo: Scritta, 1996.

LIMA, M.E.A. Contribuições da clínica da atividade para o campo da segurança no trabalho. Revista Brasileira de Saúde Ocupacional, São Paulo, v. 32, n. 115, p. 99-107, 2007.

LINHART, D. A desmedida do capital. São Paulo: Boitempo, 2007.

SCHWARTZ, Y. Le travail comme expérience et les critères du taylorisme. In: SCHWARTZ, Y. Le paradigme ergologique ou um métier de philosophe. Toulouse: Octarès, 2000.

SOUZA, P.R. Entrevista. Folha de S. Paulo, São Paulo, 15 abr. 2009. Cotidiano. Disponível em: <http://www1.folha.uol.com.br/folha/ educacao/ult305u550829.shtml>. Acesso em: mar. 2010.

TEIGER, C. et al. Trinta anos depois: reflexão sobre uma história das relaçõoes entre pesquisa em ergonomia e ação sindical na França (o caso das operárias do setor eletrônico entre 1965 e 1975). In: Figueiredo, M. et al. Labirintos do trabalho: interrogações e olhares sobre o trabalho vivo. Rio de Janeiro: DP\&A, 2004.

VIGARELLO, G. A invenção da ginástica no século XIX: movimentos novos, corpos novos. Revista Brasileira de Ciências do Esporte, Campinas, v. 25, n. 1, p. 9-20, set. 2003. 